\title{
Update on the optimal use of bortezomib in the treatment of multiple myeloma
}

This article was published in the following Dove Press journal:

Cancer Management and Research

2 March 2017

Number of times this article has been viewed

\section{Meera Mohan \\ Aasiya Matin \\ Faith E Davies}

Myeloma Institute, University of Arkansas for Medical Sciences, Little Rock, AR, USA
Correspondence: Faith E Davies Myeloma Institute, University of Arkansas for Medical Sciences, 430 West Markham, \#816, Little Rock, AR 72205, USA

Tel +I $50 \mid 5266990$ ext 8138

Email fedavies@uams.edu

\begin{abstract}
The proteasome inhibitor (PI) "bortezomib" has now been in routine clinical practice for over a decade. It is now considered an important backbone therapy for all stages of the disease, and data continue to grow to support its use in newly diagnosed patients, relapsed and relapsed/refractory disease, maintenance therapy, high risk, and renal failure. Much has been learnt about the most clinically effective way of delivering therapy, with patients often benefiting more from a triplet bortezomib combination compared to a doublet combination. It is well tolerated and can be administered in the outpatient setting with manageable toxicity. The key to good results is managing side effects so that patients remain on therapy with minimal interruptions. Therefore, proactive management of peripheral neuropathy and thrombocytopenia is advised using dose delay and reduction strategies. The recent introduction of second- and third-generation PIs with different chemical and biological properties has resulted in a plethora of new clinical studies and has confirmed the ongoing role of this class of drugs in future myeloma therapy.
\end{abstract}

Keywords: multiple myeloma, proteasome inhibitor, bortezomib, treatment

\section{Introduction}

Multiple myeloma (MM) is a relatively uncommon cancer, and the lifetime risk of being affected is one in $143(0.7 \%)$ in the USA. The American Cancer Society estimates that during 2015 in the USA, 26,850 new cases were diagnosed $(14,090$ men and 12,760 women) and 11,240 deaths were expected to occur (6,240 men and 5,000 women). Importantly, the survival of patients with myeloma has dramatically improved over the past 10 years, with a proportion of low-risk patients now being cured. ${ }^{1}$ Much of this improvement has been because of the widespread availability of the so-called "novel agents" proteasome inhibitors (PIs) and immunomodulatory drugs (IMiDs).

Bortezomib was the first PI shown to have anti-myeloma effects. It was approved by the US Food and Drug Administration's (FDA) fast-track route in 2003 following the promising results in relapsed and/or refractory patients. Since then, the evidence base for its use has expanded and numerous clinical trials have demonstrated its clinical activity in newly diagnosed and relapsed patients as well as for maintenance therapy. These studies have led to the drug being considered a backbone therapy for all patients. This review, therefore, discusses some of the key trials that support its use in myeloma and highlights the central and continuing role for PIs in myeloma therapy. 
Importantly, the review concentrates on the practical aspects of therapy and side effect management in clinical practice.

\section{Mechanism of action of bortezomib}

Bortezomib exerts its anti-myeloma action at multiple critical nodes within the myeloma cell and the bone marrow microenvironment. ${ }^{2-4}$ Its therapeutic target, the proteasome, is responsible for the degradation of key proteins required in cell cycle progression, cell growth, repair, and apoptosis. These critical proteins first undergo ubiquitination tagging and once targeted for degradation are enzymatically digested by the proteasome. Interestingly, myeloma cells appear to be more dependent on the proteasome and have a higher level of proteasome activity than normal cells.

One example of a pathway that is affected is the NF- $\kappa B$ pathway, which is important for myeloma growth and survival. The activity of the transcription factor NF- $\kappa \mathrm{B}$ is

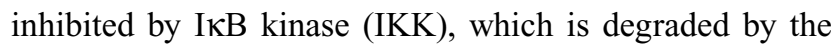
ubiquitin proteasome pathway (UPP) rendering NF- $\kappa B$ free to enter the nucleus and induce antiapoptotic genes and thus cell survival. Bortezomib reversibly inhibits the chymotrypsin enzymatic action of the proteasome; hence, IKK is unable to be degraded and continues to bind and inhibit NF- $\kappa \mathrm{B}$ resulting in myeloma cell death. Other pathways affected include the misfolding and unfolding of immunoglobulin in the endoplasmic reticulum resulting in a cellular stress response, the balance of pro- and antiapoptotic genes, such as NOXA and MCL1, and the paracrine secretion of myeloma growth and survival factors from the bone marrow stromal cells (Figure 1).

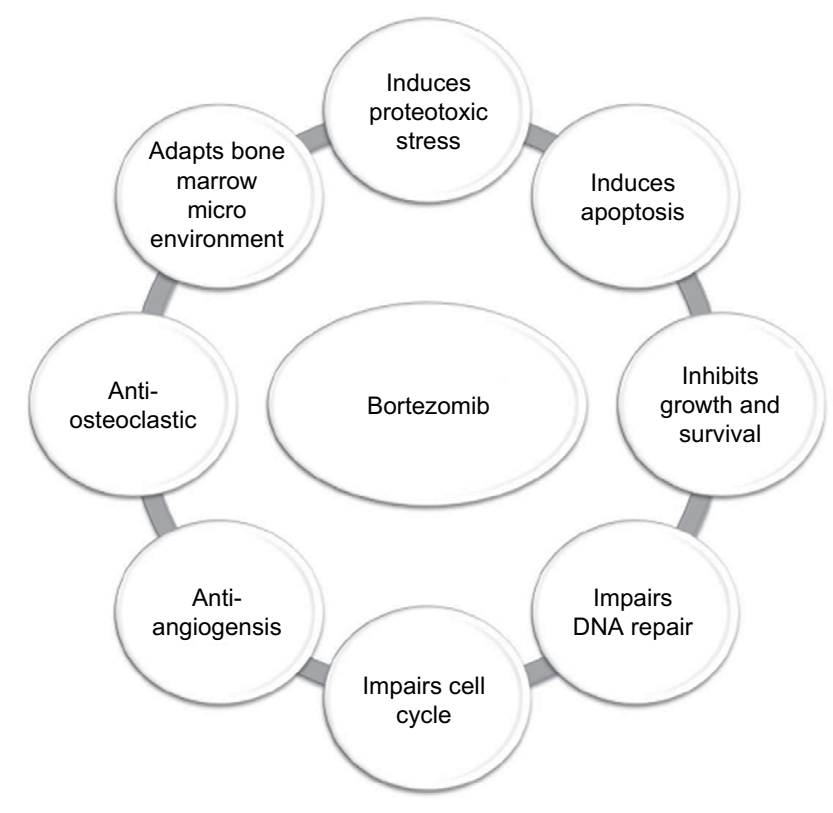

Figure I Mechanisms of action of bortezomib

\section{Bortezomib in relapsed/ refractory MM}

As with all new drugs, bortezomib was initially tested in relapsed and refractory disease (Table 1). This is a challenging clinical scenario due to the aggressiveness of the disease and preexisting toxicities from previous therapies. The initial phase II study, SUMMIT, involved 193 patients and showed a response rate of $35 \%$, proving that the drug is active in patients with relapsed disease that is refractory to conventional chemotherapy. ${ }^{5}$ Patients received bortezomib on what became the standard dosing regimen of $1.3 \mathrm{mg} / \mathrm{m}^{2}$ intravenously twice weekly for 2 weeks every 21 days for up to eight cycles. In an extended follow-up of the study, the median time to progression (TTP) for patients was 7.0 months, and for responding patients it was 13.9 months. Importantly, this translated into a median overall survival (OS) of 17.0 months for all patients, with the median OS for responding patients not being reached at the time of analysis (23 months + ). ${ }^{6-8}$

These results led to the initiation of the APEX study that compared bortezomib to high-dose dexamethasone, the standard of care for patients at that time. ${ }^{9,10}$ A total of 669 patients with relapsed myeloma were randomized to receive either intravenous bortezomib on the standard schedule $\left(1.3 \mathrm{mg} / \mathrm{m}^{2}\right.$ on days $1,4,8$, and 11 for eight 3 -week cycles, followed by treatment on days $1,8,15$, and 22 for three 5-week cycles) or high-dose dexamethasone $40 \mathrm{mg}$ orally on days 1-4, 9-12, and 17-20 for four 5-week cycles, followed by treatment on days 1-4 for five 4-week cycles. Treatment-related toxicities included grade $3 / 4$ bone marrow suppression (anemia 10\%, neutropenia $14 \%$, and thrombocytopenia $26 \%$ ), peripheral neuropathy (7\%), and diarrhea (7\%). The overall response (OR; 38\% vs 18\%) and complete response (CR; 6\% vs 1\%) were higher with bortezomib compared to dexamethasone, and this translated into a longer TTP (6.22 vs 3.49 months) and 1 -year OS (80\% vs $66 \%$ ).

A further study in relapsed or refractory disease, CREST, compared two dosing levels of bortezomib (1.0 and $1.3 \mathrm{mg} / \mathrm{m}^{2}$ ) and demonstrated substantial activity for both levels alone or in combination with dexamethasone. Side effects were less with the $1.0 \mathrm{mg} / \mathrm{m}^{2}$ regimen, particularly in relation to neuropathy (grade $3 / 4,8 \%$ vs $15 \%$ ). Survival, response, and TTP suggested that a starting dose of $1.3 \mathrm{mg} / \mathrm{m}^{2}$ was preferred, but importantly if bortezomib dose reduction was required, $1.0 \mathrm{mg} / \mathrm{m}^{2}$ still offered patients substantial benefits. ${ }^{8}$

These studies, therefore, confirmed bortezomib's effectiveness in treating myeloma and set the scene for a number of other studies exploring bortezomib combinations 
Table I Combination of bortezomib with other chemotherapeutic agents in relapsed and refractory myeloma

\begin{tabular}{|c|c|c|c|c|c|c|c|}
\hline Study drugs & Phase & Reference & OR\% & CR\% & $\begin{array}{l}\text { PFS } \\
\text { (months) }\end{array}$ & $\begin{array}{l}\text { TTP } \\
\text { (months) }\end{array}$ & Median OS \\
\hline VD & II & Richardson et $\mathrm{a}^{5,6}$ & $P R \geq 27$ & 10 & - & 7 & 17 months \\
\hline Bortezomib or VD & II & Jagannath et $\mathrm{al}^{8}$ & $P R \geq 20 ; P R \geq 38$ & II; 4 & - & 7 & 26.8 months \\
\hline $\begin{array}{l}\text { Bortezomib vs } \\
\text { dexamethasone }\end{array}$ & III & Richardson et al ${ }^{9}$ & 38 vs 18 & 6 vs 1 & - & 6.2 vs 3.5 & $80 \%$ vs $66 \%$ (at I year) \\
\hline $\begin{array}{l}\text { Bortezomib vs bortezomib } \\
\text { plus PEG-doxorubicin }\end{array}$ & III & Orlowski et al" & $4 I$ vs 44 & 2 vs 4 & 6.5 vs 9.0 & 6.5 vs 9.3 & $\begin{array}{l}65 \% \text { vs } 76 \% \\
\text { (at } 15 \text { months) }\end{array}$ \\
\hline VTD vs TD & III & Garderet et al ${ }^{12}$ & 45 vs 25 & 45 vs 21 & 18.3 vs 13.6 & 19.5 vs 13.8 & $71 \%$ vs $65 \%$ (at 2 years) \\
\hline $\begin{array}{l}\text { Lenalidomide, bortezomib, } \\
\text { and dexamethasone }\end{array}$ & II & Richardson et al ${ }^{13}$ & 64 & $\mathrm{II}$ & 9.5 & - & 30 \\
\hline $\begin{array}{l}\text { Bortezomib, dexamethasone, } \\
\text { and panobinostat vs VD }\end{array}$ & III & San-Miguel et a ${ }^{38}$ & 60.7 vs 54.6 & $\begin{array}{l}27.6 * \text { vs } \\
16.7\end{array}$ & II.9 vs 8.08 & - & 33.6 vs 30.4 \\
\hline $\begin{array}{l}\text { Panobinostat, bortezomib, } \\
\text { and dexamethasone }\end{array}$ & II & Richardson et $\mathrm{al}^{39}$ & 34.5 & 0 & 5.4 & - & Not reached \\
\hline $\begin{array}{l}\text { Vorinostat and bortezomib } \\
\text { vs bortezomib }\end{array}$ & III & Dimopoulus et $\mathrm{al}^{37}$ & 56.2 vs 40.6 & $\begin{array}{l}7.9 \text { vs } \\
5.3\end{array}$ & 7.63 vs 6.83 & 7.73 vs 7.03 & Not reached \\
\hline
\end{tabular}

Note: *Includes CR and nCR.

Abbreviations: $C R$, complete response; $n C R$, near CR; OR, overall response; OS, overall survival; PFS, progression-free survival; PR, partial response; TD, thalidomide and dexamethasone; TTP, time to progression; VD, bortezomib and dexamethasone; VTD, bortezomib, thalidomide, and dexamethasone.

with the aim of increasing response rates and inducing durable remissions. One example is a study in relapsed and refractory disease, where bortezomib in combination with liposomal doxorubicin was compared to single-agent bortezomib $(\mathrm{n}=646) .{ }^{11}$ The doublet combination led to an improved median TTP (9.3 vs 6.5 months) and OS at 15 months ( $76 \%$ vs $65 \%$ ); however, further longer follow-up of the study was disappointing and suggested little benefit for the combination.

In comparison, the results of studies with combinations of IMiDs and PIs have been very promising. One example includes a multicenter phase III study that compared the combination of bortezomib, thalidomide, and dexamethasone (VTD) to thalidomide and dexamethasone (TD) in patients relapsing after autologous transplant. ${ }^{12}$ Overall, 269 patients were randomly assigned to receive bortezomib $\left(1.3 \mathrm{mg} / \mathrm{m}^{2}\right.$ intravenously on the standard dosing schedule at that time) or no bortezomib for 1 year, in combination with thalidomide ( $200 \mathrm{mg}$ once a day orally) and dexamethasone ( $40 \mathrm{mg}$ orally once a day for 4 days every 3 weeks). Median TTP was significantly longer with VTD than TD (19.5 vs 13.8 months; hazard ratio [HR], $0.59 ; 95 \% \mathrm{CI}, 0.44-0.80 ; P=0.001$ ), the CR plus near-CR (nCR) rate was higher ( $45 \%$ vs $21 \%$; $P<0.001$ ), and the median duration of response (DOR) was longer (17.9 vs 13.4 months; $P=0.04$ ) with the 24 -month survival rate in favor of VTD $(71 \%$ vs $65 \% P=0.093)$. Overall, VTD was more effective than TD for the treatment of relapse, although there was an increased incidence of grade 3 neurotoxicity (grade 3, 29\% vs 12\%).
In addition to studies with thalidomide, other IMiD combinations have also been explored in the relapsed setting. A phase II trial involving 64 patients treated with lenalidomide, bortezomib, and dexamethasone showed the combination to be effective and tolerable in patients with relapsed and relapsed/refractory myeloma. On this occasion, bortezomib was given at a dose of $1.0 \mathrm{mg} / \mathrm{m}^{2}$ (days $1,4,8$, and 11), along with lenalidomide $15 \mathrm{mg}$ /day (days 1-14), with dexamethasone on the day of and after bortezomib dosing. Common toxicities included neuropathy (53\%), fatigue $(50 \%)$, and neutropenia (42\%). The rate of partial response (PR) or better was $64 \%$, and median DOR was 8.7 months, with a median progression-free survival (PFS) and OS of 9.5 and 30 months, respectively. ${ }^{13}$

Although we only have space to highlight a few studies mentioned earlier, there is now a wealth of data demonstrating that bortezomib as a doublet or triplet in combination with steroid, IMiDs, or chemotherapy is better than monotherapy in terms of response rate, DOR, and PFS in relapsed disease. Importantly, the addition of the second agent as in bortezomib and dexamethasone (VD) or third drug (e.g., IMiD, thalidomide, or lenalidomide) with steroid did not add significant clinical toxicity making the regimens both tolerable and effective. Following the change in the administration of bortezomib from intravenous to subcutaneous, as given in the following sections, the toxicities have also significantly reduced from these initial reports and the adoption of a triplet regimen with bortezomib has now become the preferred therapeutic approach. 


\section{Mode of delivery of bortezomib}

One of the ground-breaking studies in the development of bortezomib explored the mode of delivery of the drug. In this phase III randomized control trial, the efficacy and safety of subcutaneous versus intravenous bortezomib were compared in 222 relapsed patients. Patients received up to eight 21-day cycles, either via subcutaneous injection $(\mathrm{n}=148)$ or intravenous infusion $(\mathrm{n}=74)$. There was no loss in efficacy with similar TTP and 1-year OS between the two groups (TTP, 10.4 vs 9.4 months; 1 -year OS, $72.6 \%$ vs $76.7 \%$ ), respectively. However, the peripheral neuropathy rates were dramatically reduced by the subcutaneous route of administration (any grade, $38 \%$ vs $53 \%$; grade $3 / 4,6 \%$ vs $16 \%$, respectively). ${ }^{14,15}$ This study, therefore, demonstrated that subcutaneous bortezomib is non-inferior in efficacy to the previous standard intravenous administration and importantly showed lower rates of side effects especially peripheral neuropathy. The study was therefore practice changing, leading to the standard route of drug administration now being subcutaneous.

\section{Bortezomib in newly diagnosed patients}

The treatment choices for newly diagnosed patients have changed dramatically over the past 5 years. At the time of the original studies of bortezomib, the standard of care for newly diagnosed patients was melphalan and prednisone for older less fit patients or induction chemotherapy followed by stem cell transplant for younger fitter patients. The encouraging results of bortezomib in the relapse setting led to studies of bortezomib in both newly diagnosed transplant-eligible and transplant-ineligible patients (Table 2).

One of the first studies in this setting was a phase II open-label study that assessed the efficacy and safety of single-agent bortezomib intravenously. ${ }^{16}$ Among 64 patients, $41 \%$ had PR or better, including $9 \% \mathrm{CR} / \mathrm{nCR}$ with a median DOR of 8.4 months and a median TTP of 17.3 months with an estimated 1-year survival of $92 \%$. A total of 32 patients successfully underwent optional stem cell transplant, and bortezomib treatment was generally well tolerated. Interestingly, $20 \%$ of patients had neuropathy symptoms at baseline and this increased to $64 \%$ following therapy. This study, therefore, set the scene for further studies exploring bortezomib use, and as in the relapsed setting suggested that combination therapy should be explored, as singleagent response rates were considered poor for the newly diagnosed setting.

\section{Transplant-eligible patients}

Total therapy 3 (TT3) was one of the first clinical trials that incorporated bortezomib into a multiagent combination regimen for both induction prior to melphalan-based tandem transplant and consolidation after tandem transplant. ${ }^{1,17}$ The induction chemotherapy prior to and consolidation chemotherapy after transplantation consisted of two cycles of bortezomib, dexamethasone, thalidomide, with 4-day continuous infusion of cisplatin, doxorubicin, cyclophosphamide, and etoposide (VDT-PACE). Maintenance consisted of 3 years of VTD. At 24 months, $83 \%$ of patients had achieved at least an $\mathrm{nCR}$, which was sustained in $88 \%$ at 2 years from its onset. With a median follow-up of 20 months, 2-year estimates of event-free survival (EFS) and OS were $84 \%$ and $86 \%$, respectively. ${ }^{17}$ Toxicities of grade $>2$ included thromboembolic events and peripheral neuropathy (12\%). This study, therefore, confirmed that bortezomib can be safely combined with multiagent chemotherapy, resulting in very high complete remissions and survival rates, and set the scene for bortezomib's exploration in other upfront settings.

In the IFM 2005-01 study, 480 newly diagnosed patients were randomized to either VAD (vincristine, adriamycin, and dexamethasone) or VD induction. ${ }^{18}$ Patients were then randomized to receive consolidation therapy (dexamethasone, cyclophosphamide, etoposide, and platinum [DCEP]) or not, and then all patients received a melphalan-based autologous stem cell transplant (ASCT). Response rates were superior with VD compared to VAD (very good PR [VGPR]/CR, $37.7 \%$ vs $15.1 \%$; CR/nCR, $14.8 \%$ vs $6.4 \%$ ), and this effect persisted post transplant (VGPR/CR, $71.8 \%$ vs $51 \%$; CR/ nCR, $40.8 \%$ vs $28.8 \%$ ). The side effect profile of both regimens was similar although as expected peripheral neuropathy occurred more frequently with VD induction. Stem cell collection was successful in both groups confirming other studies that demonstrate bortezomib does not affect the ability to mobilize stem cells.

The HOVON/GMMG-HD4 phase III randomized control trial also explored the use of bortezomib as induction therapy but in addition looked at its role in the maintenance setting. ${ }^{19}$ A total of 827 newly diagnosed patients were enrolled, who were randomly assigned to receive induction therapy with VAD or bortezomib, adriamycin, and dexamethasone (PAD) followed by high-dose melphalan and ASCT. Maintenance therapy, the treatment consisted of thalidomide $50 \mathrm{mg}$ daily (VAD arm) or bortezomib $1.3 \mathrm{mg} / \mathrm{m}^{2}$ (PAD arm) once every 2 weeks for 2 years. $\mathrm{CR} / \mathrm{nCR}$ was superior after PAD induction $(15 \%$ vs $31 \% ; P<0.001)$ and bortezomib 
Table 2 Combination of bortezomib with other chemotherapeutic agents in newly diagnosed myeloma

\begin{tabular}{|c|c|c|c|c|c|c|c|}
\hline Study drugs & Reference & OR\% & $\mathbf{C R} \%$ & PFS (months) & $\begin{array}{l}\text { TTP } \\
\text { (months) }\end{array}$ & $\begin{array}{l}\text { Median OS } \\
\text { (months) }\end{array}$ & $\begin{array}{l}\text { Median } \\
\text { follow-up } \\
\text { (months) }\end{array}$ \\
\hline $\begin{array}{l}\text { VDT-PACE: induction }+ \\
\text { consolidation, } 2 \times \text { melphalan } \\
\text { ASCT }\end{array}$ & Barlogie et al' & - & 83 & $84 \%$ at 2 years & - & $\begin{array}{l}88 \% \text { at } \\
2 \text { years }\end{array}$ & 20 \\
\hline $\begin{array}{l}\text { VAD induction/high-dose } \\
\text { melphalan ASCT/maintenance } \\
\text { thalidomide; PAD induction/ } \\
\text { high-dose melphalan ASCT/ } \\
\text { maintenance bortezomib }\end{array}$ & Sonneveld et a $\left.\right|^{19}$ & $83 ; 91$ & $34 ; 49$ & $28 ; 35$ & - & $\begin{array}{l}78 \text { ( } 3 \text { years); } \\
70 \text { ( } 3 \text { years) }\end{array}$ & 41 \\
\hline $\begin{array}{l}\text { Intl: VD and no consolidation } \\
\text { Intl2: VD plus DCEP as } \\
\text { consolidation } \\
\rightarrow \text { ASCT } \\
\text { Control I: VAD and no } \\
\text { consolidation } \\
\text { Control 2: VAD plus DCEP as } \\
\text { consolidation } \\
\rightarrow \text { ASCT }\end{array}$ & Harousseau et al ${ }^{18}$ & $\begin{array}{l}\text { Post } \\
\text { induction: } \\
78.5 ; \text { post } \\
\text { induction: } \\
62.8\end{array}$ & $\begin{array}{l}\text { Post induction: } \\
\text { 14.8; post first } \\
\text { transplant: } 40.8 \text {; } \\
\text { post induction: } \\
6.4 \text {; post first } \\
\text { transplant: } 28.8\end{array}$ & $36 ; 29.7$ & - & Not reached & 32.2 \\
\hline VTD vs TD & Cavo et $\mathrm{a}^{20}$ & 92 vs 78.5 & $\begin{array}{l}\text { Induction: } 33 \\
\text { vs I2; after } \\
\text { transplant: } 4 \text { I } \\
\text { vs } 20\end{array}$ & $93 \%$ vs $86 \%$ & & $\begin{array}{l}\text { Not } \\
\text { statistically } \\
\text { significant (at } \\
20 \text { months) }\end{array}$ & 15 \\
\hline VTD vs VCD & Moreau et $\mathrm{al}^{22}$ & $\begin{array}{l}92.3 \text { vs } \\
83.4\end{array}$ & I3.0 vs 8.9 & - & - & - & - \\
\hline $\begin{array}{l}\text { Bortezomib, melphalan, and } \\
\text { prednisolone vs melphalan and } \\
\text { prednisolone }\end{array}$ & San Miguel et $\mathrm{a}^{24}$ & 71 vs 35 & 30 vs 4 & - & 24 vs 16.6 & NE & 36.7 \\
\hline $\begin{array}{l}\text { Induction: bortezomib, melphalan, } \\
\text { and prednisolone vs bortezomib, } \\
\text { thalidomide, and prednisolone. } \\
\text { Maintenance: bortezomib and } \\
\text { thalidomide vs bortezomib and } \\
\text { prednisolone }\end{array}$ & Mateos et $\mathrm{al}^{25}$ & $\begin{array}{l}\text { Induction: } \\
81 \text { vs } 80\end{array}$ & $\begin{array}{l}\text { Induction: } \\
28 \text { vs } 20 \text {; after } \\
\text { maintenance: } \\
44 \text { vs } 39\end{array}$ & $\begin{array}{l}\text { Median } 31 . \\
\text { No statistical } \\
\text { difference }\end{array}$ & $\begin{array}{l}\text { Median } \\
\text { 35. No } \\
\text { statistical } \\
\text { difference }\end{array}$ & $\begin{array}{l}\text { 3-year OS, } \\
70 \% . \text { No } \\
\text { statistical } \\
\text { difference }\end{array}$ & 32 \\
\hline $\begin{array}{l}\text { Bortezomib, lenalidomide, and } \\
\text { dexamethasone vs lenalidomide } \\
\text { and dexamethasone }\end{array}$ & Durie et $\mathrm{a}^{26}$ & - & - & 43 vs 31 & - & $\begin{array}{l}\text { Not reached } \\
\text { vs } 63\end{array}$ & - \\
\hline $\begin{array}{l}\text { VD vs bortezomib, lenalidomide, } \\
\text { and dexamethasone vs } \\
\text { bortezomib, melphalan, and } \\
\text { prednisolone }\end{array}$ & Niesvizky et a ${ }^{31}$ & $\begin{array}{l}73 \text { vs } 80 \\
\text { vs } 70\end{array}$ & 3 vs 4 vs 4 & $\begin{array}{l}\text { I } 4.7 \text { vs } 15.4 \text { vs } \\
17.3\end{array}$ & - & $\begin{array}{l}49.8 \text { vs } 51.5 \\
\text { vs } 53.1\end{array}$ & 42.7 \\
\hline
\end{tabular}

Note: VDT-PACE, bortezomib, dexamethasone, thalidomide, with 4-day continuous infusion of cisplatin, doxorubicin, cyclophosphamide, and etoposide.

Abbreviations: ASCT, autologous stem cell transplant; CR, complete response; DCEP, dexamethasone, cyclophosphamide, etoposide, and platinum; Intl, interventional; NE, not estimable; OR, overall response; OS, overall survival; PAD, bortezomib, adriamycin, and dexamethasone; PFS, progression-free survival; TD, thalidomide and dexamethasone; TTP, time to progression; VAD, vincristine, adriamycin, and dexamethasone; VCD, bortezomib, cyclophosphamide, and dexamethasone; VD, bortezomib and dexamethasone; VTD, bortezomib, thalidomide, and dexamethasone.

maintenance $(34 \%$ vs $49 \% ; P<0.001)$. After a median follow-up of 41 months, PFS was superior in the PAD arm (median of 28 vs 35 months; HR, $0.75 ; 95 \%$ CI, $0.62-0.90$; $P=0.002)$, as was OS (HR, 0.77; 95\% CI, 0.60-1.00; $P=0.049)$. The study, therefore, confirmed and extended the results of the Intergroupe Francophone du Myélome (IFM) group by demonstrating that bortezomib during induction and maintenance improves $\mathrm{CR}$ and achieves superior PFS and OS.
As in the relapsed setting, the IMiD/PI combination has also been explored. The Italian group (GEM05MENOS65) randomized newly diagnosed patients to TD (thalidomide $200 \mathrm{mg}$ daily with dexamethasone $40 \mathrm{mg}$ on days $1-4$ and 9-12 of each 21-day cycle), with or without the addition of bortezomib (TD vs VTD) ${ }^{20}$ Patients treated with VTD had superior response rates compared to TD (OR, $92 \%$ vs $78.5 \%$; VGPR or better, $61 \%$ vs $30 \%$; CR/nCR, $33 \%$ vs $12 \%$ ). As 
with the previous two studies, peripheral neuropathy was higher in the bortezomib-containing arm, and there was no evidence of impairment of stem cell collection following bortezomib therapy. Following ASCT, those who received VTD had improved response rates compared to TD (VGPR or better, $75 \%$ vs $53 \%$; CR/nCR, $54 \%$ vs $29 \%$; CR rate, $41 \%$ vs $20 \%$ ). Although the follow-up was short at the time of the report (15 months), PFS was improved in the VTD arm (93\% vs $86 \%$ ), while the 20 -month OS rate was equivalent in the two arms.

An individual patient meta-analysis of these three upfront studies has recently been performed to further study the efficacy and safety of bortezomib-based versus non-bortezomibbased induction regimens in transplant-eligible patients (IFM 2005-01 [VD vs VAD], HOVON-65/GMMG-HD4 [PAD vs VAD], and PETHEMA GEM05MENOS65 [VTD vs TD]). ${ }^{18-21}$ Of the 1,572 patients, 787 received bortezomibbased induction and 785 non-bortezomib-based induction. Post transplantation, $\mathrm{CR} / \mathrm{nCR}$ rate was significantly higher following bortezomib-based versus non-bortezomib-based induction (38\% vs $24 \%$; odds ratio, $2.05 ; P=0.001$ ); the median PFS was 35.9 versus 28.6 months with bortezomibbased versus non-bortezomib-based induction, respectively (HR, 0.75; $P<0.001$ ); and 3-year OS rates were $79.7 \%$ and $74.7 \%$, respectively (HR for OS, $0.81 ; P=0.04$ ). The median duration of induction treatment was 11 weeks in both treatment groups. Rates of peripheral neuropathy were higher with the bortezomib regimen (any grade, 34\% vs 17\%; grade 3 , $6 \%$ vs $1 \%$ ); however, it is important to note that these studies were performed with the intravenous route of bortezomib administration, and so rates would be expected to be less with the subcutaneous route. Therefore, the overwhelming conclusion of these studies is that bortezomib-based induction results in significant improvement in response and PFS/ OS but has a higher rate of peripheral neuropathy.

Provocative results from a French study have recently been released looking at two different bortezomib-containing regimens as induction chemotherapy (four courses) prior to transplantation, VTD, and bortezomib, cyclophosphamide, and dexamethasone (VCD). ${ }^{22}$ A total of 358 patients were randomized to VTD (as mentioned earlier) or VCD (bortezomib subcutaneous $1.3 \mathrm{mg} / \mathrm{m}^{2}$ on days $1,4,8$, and 11 , dexamethasone $40 \mathrm{mg}$ po on days $1-4$ and 9-12, and cyclophosphamide $500 \mathrm{mg} / \mathrm{m}^{2}$ on days 1,8 , and 15 ). The OR rate, CR, and VGPR rate were $92.3 \%, 10.7 \%$, and $66.7 \%$ for VTD and $84 \%, 9.5 \%$, and $36.2 \%$ for CVD, respectively. The differences in VGPR and PR rates were statistically significant $(P=$ 0.04 and $P=0.02$, respectively). As expected, neutropenia rates were higher in the VCD arm (33.1\% vs $18.9 \%)$ and neuropathy rates were lower $(7.7 \%$ vs $29 \%)$. These results, therefore, suggest that a three-drug regimen (either VTD or VCD) gives better response rates than the two-drug regimen of VD, and that the IMiD/PI may be optimum.

As in the relapsed setting, bortezomib has now also been combined with the newer IMiD, lenalidomide in newly diagnosed patients with impressive results. A total of 66 patients received bortezomib, lenalidomide, and dexamethasone followed by either maintenance therapy or transplantation. ${ }^{23}$ Optimum dosing was determined to be bortezomib $1.3 \mathrm{mg} / \mathrm{m}^{2}$ (days $1,4,8$, and 11), lenalidomide $25 \mathrm{mg}$ (days 1-14), and dexamethasone $20 \mathrm{mg}$ (on the day of and day after bortezomib), with the most common toxicities included sensory neuropathy (all grades, $80 \%$; grade 2, 27\%; grade 3, 2\%) and fatigue (all grades, $64 \%$; grade $2,27 \%$; grade $3,3 \%$ ). No treatment-related mortality was observed. The rate of PR or better was $100 \%$, with $74 \%$ of patients achieving a VGPR or CR. Approximately $42 \%$ of patients proceeded to transplantation. With a median follow-up of 21 months, estimated 18-month PFS and OS were $75 \%$ and $97 \%$, respectively. The authors, therefore, concluded that revlimid velcade dexamethasone (RVD) demonstrated favorable tolerability and was highly effective in the treatment of newly diagnosed myeloma. Based on these data, RVD has now become a standard induction therapy for both younger fitter and older less fit patients, particularly in the USA. In combination with the experience of RVD in the relapsed setting, outside of the context of a clinical trial, data would suggest that it is possible to adjust the frequency and dose of both bortezomib ( $1 \mathrm{mg} / 1.3 \mathrm{mg}$ biweekly/weekly) and lenalidomide $(15 \mathrm{mg} / 25 \mathrm{mg})$ to ensure that patients can clinically benefit from therapy with minimal side effects.

\section{Transplant-ineligible patients}

Studies of patients who are older and less fit also demonstrate a significant benefit for bortezomib therapy (Table 2). At the time the initial studies were started, standard induction was with oral melphalan with or without steroids. One of the first large, multicenter phase III trials involved 682 patients with newly diagnosed myeloma and compared bortezomib plus melphalan and prednisone (VMP) to melphalan prednisolone (MP) alone. ${ }^{24}$ Patients received melphalan $9 \mathrm{mg} / \mathrm{m}^{2}$ with prednisone $60 \mathrm{mg} /$ $\mathrm{m}^{2}$ on days $1-4$ of each 6 -week cycle. Bortezomib was added to MP in the VMP arm at a dose of $1.3 \mathrm{mg} / \mathrm{m}^{2}$ on days $1,4,8,11$, $22,25,29$, and 32 during cycles $1-4$ and on days $1,8,22$, and 29 during cycles 5-9. Patients treated with VMP had improved response rates (CR rate, $30 \%$ vs $4 \%$ ), prolonged TTP (24 vs 16.6 months), and prolonged DOR (19.9 vs 13.1 months). 
The toxicity profile was in keeping with the previous experience of MP and bortezomib as single agents with toxicities more common with VMP than MP (grade 3, 53\% vs 44\%). In this initial study, bortezomib was delivered intravenously and $13 \%$ of participants in the VMP arm experienced grade 3 neuropathy, while one patient developed grade 4 neuropathy.

Due to the significant toxicities reported in the abovementioned study, a phase III randomized control trial was initiated that investigated a lower-intensity bortezomib regimen. This study enrolled 260 untreated patients who were 65 years and older. ${ }^{25}$ The patients were randomized to receive six cycles of VMP or VTP as induction therapy, consisting of one cycle of bortezomib $1.3 \mathrm{mg} / \mathrm{m}^{2}$ twice per week for 6 weeks, plus either melphalan $\left(9 \mathrm{mg} / \mathrm{m}^{2}\right.$ on days $\left.1-4\right)$ or daily thalidomide (100 mg), and prednisone (60 mg/m² on days $1-4)$. The first cycle was followed by five cycles of bortezomib only once per week for 5 weeks with the same doses of MP or TP. A total of 178 patients completed induction therapy and were randomized to maintenance therapy with velcade prednisolone (VP) or velcade thalidomide (VT). This consisted of one conventional cycle of bortezomib for 3 weeks every 3 months, plus either prednisone (50 mg alternate days) or thalidomide (50 mg per day), for up to 3 years. In the induction phase, $81 \%$ patients in the VTP group and $80 \%$ in the VMP group achieved PR or better $(P=0.9)$, including $28 \%$ and $20 \%$ CRs, respectively $(P=0.2)$. Treatment with VTP resulted in more serious adverse events (AEs; $31 \%$ vs $15 \%$, $P=0.01)$ and discontinuations $(17 \%$ vs $12 \%, P=0.03)$ than treatment with VMP. The most common grade 3-4 toxicities were infections ( $1 \%$ vs $7 \%$ ), cardiac events ( $8 \%$ vs $0 \%$ ), and peripheral neuropathy (7\% vs $9 \%)$. After maintenance therapy, the CR rate was $42 \%$ (44\% in the VT group and $39 \%$ in the VP group). No grade 3 or higher hematological toxicities were recorded during maintenance therapy, although a further $2 \%$ of patients in the VP group and $7 \%$ in the VT group developed peripheral neuropathy. This study showed that dose-reduced bortezomib was a well-tolerated and effective treatment in elderly patients and has led to the preferred regimen of weekly dosing in this patient group.

The combination of velcade revlimid dexamethasone (VRD) has also been explored in the non-transplant setting. Bortezomib was given on a once weekly schedule in combination with lenalidomide $25 \mathrm{mg}$ for 14 days with dexamethasone and compared to standard lenalidomide and dexamethasone alone (RD). ${ }^{26}$ A total of 525 patients were randomized in the study. The median PFS and OS were improved in the VRD arm (43 vs 31 months; not reached vs 63 months). The toxicity rate in each arm was similar, although the pattern was different, with sensory neuropathy being more common in the RVD arm (23\% vs 3\%). The study, therefore, confirms the efficacy of weekly bortezomib, highlights the necessity for managing emergent side effects, and also suggests the efficacy of a three-drug regimen compared to a two-drug regimen.

\section{Bortezomib in special situations Renal impairment and failure}

It is well documented that renal impairment may be a significant problem in myeloma. Approximately 30\% of patients present with baseline renal dysfunction, of which $1-13 \%$ require dialysis support. As the disease progresses, the incidence of renal failure and renal impairment also increases. Renal failure has been associated with a shorter survival, and its presence offers significant challenges for the delivery of therapy as many patients with renal failure suffer an increased incidence of treatment-related side effects or require the dose/frequency of anti-myeloma therapy to be adjusted. ${ }^{27,28}$

A retrospective case analysis evaluated the feasibility and activity of bortezomib-based therapy in patients with myeloma $(n=24)$ requiring dialysis support for advanced renal failure. ${ }^{29}$ Patients received either bortezomib alone or in combination with chemotherapy. Among 20 patients with available response data, the OR rate (CR/PR) was 75\%, with $30 \% \mathrm{CR} / \mathrm{nCR}$. One patient was spared dialysis, and three other patients became independent of dialysis following therapy. These results demonstrate that bortezomib-based regimens can be used in patients with myeloma requiring dialysis, with manageable toxicities. Importantly, the dosing regimen did not need to be altered for patients depending on their creatinine clearance and response rates were fast, making bortezomib one of the therapies of choice for patients with renal impairment or renal failure. Similar results have been seen in the newly diagnosed setting. In the HOVON/ GMMG-HD4 study, transplant patients presenting with increased creatinine of $>2 \mathrm{mg} / \mathrm{dL}$ had significantly improved PFS from a median of 13-30 months (HR, 0.54; 95\% CI, $0.26-0.78 ; P=0.004)$ when treated with bortezomib and $\mathrm{OS}$ increased from a median of 21 to 54 months (HR, $0.33 ; 95 \%$ CI, 0.16-0.65; $P<0.001) .{ }^{19}$

\section{Frail patients}

Frail elderly patients represent a particularly challenging population due to preexisting comorbidities that can complicate their management and outcome. The goal of treatment in this population is often more focused on symptom control, improvement in overall functional status, and quality of life. Minimizing the toxicity of any treatment regimen is 
important, so that patients can tolerate therapy and remain on it to benefit. ${ }^{30}$

In a randomized open-label study, newly diagnosed patients with myeloma who were ineligible for stem cell transplant because of age ( $\geq 65$ years), comorbidities, or personal preference were randomly assigned 1:1:1 to receive eight 21-day cycles of VD, VTD, or VMP induction followed by five 35-day cycles of maintenance with single-agent intravenous bortezomib $1.6 \mathrm{mg} / \mathrm{m}^{2}$ on days $1,8,15$, and $22 .{ }^{31}$ Median PFS with VD, VTD, and VMP was 14.7, 15.4, and 17.3 months, respectively; median OS was 49.8, 51.5, and 53.1 months, with no significant differences among treatments for either end point (global $P=0.46$ and $P=0.79$, respectively). AEs and discontinuations were higher in the VTD patients including neuropathy (grade 2 or greater, $47 \%$ vs $35 \%$ vs $35 \%$ ). OR rates were $73 \%$ (VD), $80 \%$ (VTD), and $70 \%$ (VMP). This study, therefore, suggests that in this elderly frail population the two-drug regimen (VD) did not appear to offer an advantage compared to the three-drug regimens mainly due to the need for dose reduction/delays and a lack of tolerability of the more complicated regimens.

\section{High-risk genetic subgroup}

A number of genetic subgroups of myeloma are known to have a poor OS with traditional chemotherapy approaches. These patients are often separated into two groups, high risk and ultra high, based on the type and number of abnormalities (e.g., t(4;14), t(14;16), del17p, and 1q/p abnormalities). ${ }^{32}$ The introduction of PIs although not completely overcoming some of these high-risk features has certainly improved the outcome for these patients. ${ }^{33}$

A matched-pair analysis from SUMMIT and APEX reported that the activity of bortezomib was consistent regardless of clinical and genetic risk factors. In the upfront transplant setting, TT3 showed that bortezomib eliminated the negative impact of $\mathrm{t}(4 ; 14)$ on PFS, ${ }^{1,34-36}$ and the HOVON study demonstrated a benefit for patients with deletion $17 \mathrm{p}$ (median PFS, 12 vs 22 months; HR, 0.47; 95\% CI, 0.26-0.86; $P=0.01$; median OS, 24 months vs not reached at 54 months; HR, 0.36; $95 \% \mathrm{CI}, 0.18-0.74 ; P=0.003$ ) as well as for patients with a $\mathrm{t}(4: 14) \cdot{ }^{18,19}$ Similar results have been seen in the non-transplant setting (e.g., melphalan prednisolone velcade [MPV]). ${ }^{24,25}$

\section{Bortezomib in combination with newer agents}

More recent studies have explored the combination of bortezomib with a number of new agents. In vitro and in vivo experiments have demonstrated that a combination of inhibitors of protein homeostasis mechanisms may be an effective anti-myeloma strategy, such as PIs with histone deacetylase or aggresome inhibitors. These laboratory studies have been shown to transfer to the clinical environment with trials of the combination of bortezomib and vorinostat, or bortezomib and panobinostat, both histone deacetylase inhibitors, showing promise.

The first study explored the combination of bortezomib with vorinostat in a randomized, double-blind, placebo-controlled, phase III trial in 635 patients with relapsed/refractory myeloma who had received between one and three previous treatment regimens (VANTAGE). ${ }^{37}$ Patients were randomized to receive standard intravenous bortezomib $\left(1.3 \mathrm{mg} / \mathrm{m}^{2}\right.$ on days $1,4,8$, and 11) in combination with oral vorinostat (400 mg) or placebo once daily on days $1-14$. The median PFS was 7 vs 63 months in the vorinostat/bortezomib group and 6 vs 83 months in the bortezomib-alone group $(P=0.01)$. The most common grade 3-4 AEs were thrombocytopenia, neutropenia, and anemia. The clinical relevance of this small difference in PFS is not clear; the small survival difference was mainly believed to be due to a lack of long-term tolerability of the combination leading to the suggestion that different treatment schedules of bortezomib and vorinostat might improve tolerability and enhance activity.

A second histone deacetylase inhibitor, panobinostat, has also been explored, this time in combination with VD, in the PANORAMA 1 study. ${ }^{38}$ The entry criteria of this multicentre, randomized, placebo-controlled, double-blind, phase III trial were similar to the abovementioned VANTAGE study. Patients were randomized to receive 21-day cycles of placebo or panobinostat (20 mg on days $1,3,5,8,10$, and 12 , orally), both in combination with bortezomib $\left(1.3 \mathrm{mg} / \mathrm{m}^{2}\right.$ on days $1,4,8$, and 11, intravenously) and dexamethasone (20 mg on days $1,2,4,5,8,9,11$, and 12 , orally). The median PFS was significantly longer in the panobinostat group than in the placebo group (11.99 months [95\% CI, 10.33-12.94] vs 8.08 months [7.56-9.23]; HR, 0.63; 95\% CI, 0.52-0.76; $P<0.0001)$, and at the time of analysis, the median OS was 33.64 months (95\% CI, 31.34 - not estimable) for the panobinostat group and 30.39 months (26.87 - not estimable) for the placebo group (HR, 0.87; 95\% CI, 0.69-1.10; $P=0.26) .{ }^{38}$ Common grade 3/4 AEs included thrombocytopenia, fatigue, and diarrhea. An additional study, PANORAMA 2, was also undertaken, where panobinostat in combination with VD was used to treat patients with relapsed and bortezomib-refractory disease (defined as at least two prior lines of therapy, including an IMiD, and patients who had progressed on or within 60 days of the last bortezomib-based therapy). ${ }^{39}$ This study 
showed that the combination of panobinostat, bortezomib, and dexamethasone can recapture responses in heavily pretreated, bortezomib-refractory patients. Both studies were used to support the licensing approval of panobinostat in combination with bortezomib that was granted in 2015 .

\section{Management of side effects of bortezomib}

One of the most common side effects of bortezomib is peripheral neuropathy (Table 3 ). With active monitoring, the incidence and severity can be dramatically reduced ensuring that patients can continue to benefit from therapy. The peripheral neuropathy is predominantly sensory with common symptoms including burning paresthesia, hyperesthesiahypoesthesia, neuropathic pain, and weakness. Importantly, although severe neuropathy was initially reported to be more frequent in patients who had baseline neuropathy, more recent studies suggest that this is not the case. ${ }^{40}$ In many instances, the neuropathy is reversible, and hence close monitoring and prompt action are imperative.

The most detailed data on the outcome of neuropathy come from patients enrolled in the initial SUMMIT and CREST studies. ${ }^{6,840}$ Of the 256 patients included in the analysis, 90 patients experienced treatment-emergent peripheral neuropathy of which 35 experienced either grade 3 or 4

Table 3 Recommended dose modification for bortezomibrelated neuropathy and/or neuropathy pain

\begin{tabular}{|c|c|c|}
\hline Severity & $\begin{array}{l}\text { Symptoms and signs of } \\
\text { peripheral neuropathy }\end{array}$ & Dose modification \\
\hline Grade I & $\begin{array}{l}\text { Asymptomatic: loss of } \\
\text { deep tendon reflexes or } \\
\text { paresthesia (including } \\
\text { tingling) but not interfering } \\
\text { with function }\end{array}$ & $\begin{array}{l}\text { Monitor closely and } \\
\text { consider dose reduction to } \\
\text { either } 1.3 \mathrm{mg} / \mathrm{m}^{2} \text { weekly or } \\
1.0 \mathrm{mg} / \mathrm{m}^{2}\end{array}$ \\
\hline $\begin{array}{l}\text { Grade } 2 \\
\text { or grade I } \\
\text { with pain }\end{array}$ & $\begin{array}{l}\text { Sensory alteration or } \\
\text { paresthesia (including } \\
\text { tingling or calf cramps } \\
\text { at night) interfering with } \\
\text { function but not with } \\
\text { activities of daily living }\end{array}$ & $\begin{array}{l}\text { Consider withholding } \\
\text { bortezomib for } 1-2 \text { weeks } \\
\text { until toxicity resolves, } \\
\text { then reduce bortezomib } \\
\text { to } 1.0 \mathrm{mg} / \mathrm{m}^{2} \text { ( } 25 \% \text { dose } \\
\text { reduction) and change to } \\
\text { weekly dosing }\end{array}$ \\
\hline $\begin{array}{l}\text { Grade } 3 \\
\text { or grade } 2 \\
\text { with pain }\end{array}$ & $\begin{array}{l}\text { Sensory alteration or } \\
\text { paresthesia interfering } \\
\text { with activities of daily living }\end{array}$ & $\begin{array}{l}\text { Withhold bortezomib until } \\
\text { toxicity resolves, then } \\
\text { restart at } 0.7 \mathrm{mg} / \mathrm{m}^{2} \text { ( } 50 \% \\
\text { dose reduction) on a weekly } \\
\text { schedule }\end{array}$ \\
\hline Grade 4 & $\begin{array}{l}\text { Permanent sensory loss } \\
\text { interfering with function } \\
\text { (disabling) }\end{array}$ & Discontinue bortezomib \\
\hline
\end{tabular}

Note: National Cancer Institute. Common terminology criteria for adverse events v3.0 (online) 2003. ${ }^{51}$ neuropathy and/or neuropathy leading to the discontinuation of treatment. Dose reduction was required in $12 \%$ of patients, and at least one course of bortezomib was withheld because of neuropathy in $7 \%$ of patients. The onset of peripheral neuropathy was typically by the end of cycle 5 . The neuropathy is believed to be dose related, but only up to a cumulative dose of $26 \mathrm{mg} / \mathrm{m}^{2}$ beyond which the effect plateaus. ${ }^{40} \mathrm{~A}$ further study has looked at the length of time until resolution of neuropathy symptoms. In 64 patients who were treated with single-agent bortezomib, neuropathy symptoms became manageable or resolved in $85 \%$ of patients in a median of 98 days. ${ }^{16}$ As discussed earlier, these initial studies used the intravenous administration route, and more recent studies show that the incidence has dramatically reduced by using subcutaneous administration and weekly scheduling. ${ }^{14,15}$

Clinically being proactive and aiming to stop neuropathy occurring are essential via dose reduction, change in dosing schedule, and supportive care. ${ }^{10}$ For instance, depending on the CTCAE grade of neuropathy, decreasing the dose from 1.3 to $1 \mathrm{mg} / \mathrm{m}^{2}$ or $0.7 \mathrm{mg} / \mathrm{m}^{2}$ is often effective when neuropathy first occurs or reducing the frequency from twice weekly to weekly or every fortnight. Critical in these steps is withholding therapy as soon as symptoms occur, as managing symptoms once side effects have occurred is difficult. Practically asking patients a number of simple questions prior to the delivery of their therapy (e.g., occurrence of leg numbness, change in leg temperature, or leg cramps particularly at night) appears to be an effective screening and monitoring approach. Thus, involving the nursing staff in the clinical plan and its delivery is key. Patients will often mention their symptoms earlier to the nursing team than they will to the medical team, enabling dose modifications to occur quickly and efficiently. In addition, educating the patient about what symptoms to expect, that the development of symptoms does not necessarily mean stopping therapy, and that once symptoms develop although they should improve this can take a considerable amount of time. Seeking a neurology opinion or nerve conduction study is rarely required. If a patient does develop neuropathy, then the most effective approach is to hold the therapy until symptoms resolve and then to initiate dose reductions. If the neuropathy is painful, then the use of gabapentin and pregabalin is often helpful. Initial dosing with gabapentin starts at $200 \mathrm{bd}$ increasing to $600 \mathrm{mg}$ tds, whereas pregabalin is $75 \mathrm{mg}$ od. In both instances, patients should be warned about drowsiness and the fact that the medications may take a number of weeks to demonstrate a significant effect. In some instances, opioid analgesia may also be required and thus seeking assistance from experts in 
chronic pain management is beneficial. Vitamin D levels may be low in patients with severe neuropathy and therefore measuring levels and replacement therapy may be appropriate. Many patients find that vitamin B12, vitamin B6, capsaicin, or menthol cream or massage therapy may also help.

When bortezomib was delivered intravenously, autonomic neuropathy was also an issue with a number of patients either complaining of orthostatic hypotension or diarrhea following dosing. These side effects have become much less frequent since dosing has moved to the subcutaneous route; however, they may still occur and should be monitored for. Adjustment of hypertension medications and the use of intravenous fluids and antidiarrheals may be required.

Thrombocytopenia can also be a limiting factor for therapy. The reason for thrombocytopenia is different compared to other chemotherapeutic agents, as bortezomib interferes with megakaryocyte maturation rather than stem cell dysfunction. The effect is an on-target effect as proteasome inhibition prevents the activation of $\mathrm{NF}-\kappa \mathrm{B}$, thereby preventing platelet budding from megakaryocytes during treatment. ${ }^{41}$ In the early SUMMIT and CREST studies, grade 3 cyclic thrombocytopenia was reported in $24-28 \%$ of cases. It was transient and predictable in nature, decreasing during the injection period (days 1, 4, 8, and 11 schedule) and returning to baseline during the 10-day rest period between cycles. It was also more frequently observed in patients with low platelet counts at baseline. From a clinical standpoint as the reduction is transient and predictable, transfusion support is rarely required. To maximize the likelihood of benefit from bortezomib therapy, patients with thrombocytopenia and active disease should be supported with platelet transfusions, as clinically indicated, as they initiate therapy rather than having treatment reduced or delayed because of thrombocytopenia. Often, as patients respond to therapy, their counts improve and transfusions are no longer required.

A localized skin rash may occur following subcutaneous delivery. Usually, this is a slightly raised erythematous patch measuring up to $3 \mathrm{~cm}$ in diameter (although if the patient is also thrombocytopenic, this may be more pronounced) at the injection site that lasts 3-7 days. Rotating sites of injection is, therefore, important. Very occasionally, a more dramatic widespread rash may occur; if this happens, then further advice from the dermatologists should be sought.

Bortezomib therapy also increases the risk of viral infections such as varicella zoster virus (VZV) and herpes simplex virus (HSV) due to its immunosuppressive effects on T cells. ${ }^{42}$ Compared to patients treated with high-dose dexamethasone, bortezomib recipients had a fourfold higher incidence of VZV infection $(13 \%$ vs $2 \% ; P<0.001) .{ }^{43}$ Therefore, it is recommended that all patients receive antiviral therapy while receiving bortezomib treatment. The risk of other infections mirrors that of newer anti-myeloma therapies, and therefore the standard of care for anti-infective management is recommended.

\section{Newer-generation PIs}

Following the success of bortezomib, a number of secondand third-generation PIs have been developed. Modifications include irreversible proteasome inhibition compared to reversible, inhibition of all three enzymatic sites compared to just the chymotrypsin site, and an oral formulation. Clinical studies are underway, but the results suggest that these modifications result in a different side effect profile to bortezomib, and in some instances patients who were resistant to bortezomib are sensitive to the newer agents.

Carfilzomib is a second-generation irreversible PI inhibiting the chymotrypsin-like site. In 2012, the FDA granted fast-track approval for carfilzomib for patients who have received at least two prior therapies including bortezomib and an IMiD (thalidomide or lenalidomide) and had demonstrated disease progression on or within 60 days of completion of last therapy. The approval was based on the results of the Phase IIB PX-171-003-A1 trial. ${ }^{44}$ The trial examined carfilzomib's efficacy in 257 heavily pretreated patients who had received a median of five prior therapies. Carfilzomib $\left(27 \mathrm{mg} / \mathrm{m}^{2}\right.$ on days $1,2,8,9,15$, and 16 of a 28 -day cycle) was found to have an ORR of $23.7 \%$, improving to $37 \%$ when minor responses (MRs) were included. DOR was 7.8 months, with median TTP of 3.9 months and an OS of 15.6 months. Treatmentrelated grade 3-4 AEs included fatigue (7.5\%), acute kidney injury (3.4\%), and dyspnea (3.4\%). Hematologic grade 3-4 AEs included anemia (24\%) and thrombocytopenia (29\%). ${ }^{44}$

Two large phase III randomized studies have recently reported and confirm the drugs' tolerable safety profile and anti-myeloma activity in relapsed patients. In ENDEAVOR, carfilzomib (56 mg/m²) and dexamethasone (KD) were compared to VD for the treatment of relapsed patients. ${ }^{45}$ The median PFS of patients assigned to KD was 18.7 months compared to 9.4 months for patients assigned to VD (HR, 0.53 ; 95\% CI, 0.44-0.65). The most frequent grade $3 / 4$ AEs included anemia, hypertension, thrombocytopenia, and pneumonia. In the second study, 792 patients with relapsed disease were randomized to carfilzomib, lenalidomide, and dexamethasone (KRD) or RD. ${ }^{46}$ The median PFS was significantly improved with the addition of carfilzomib (26.3 vs 17.6 months; HR, 0.69; 95\% CI, 0.57-0.83; $P=0.0001)$. The rates of OR (PR or better) were $87.1 \%$ and $66.7 \%$ 
$(P<0.001)$, respectively, and $31.8 \% / 14.1 \%$ and $9.3 \% / 4.3 \%$ of patients had a CR/stringent CR (SCR), respectively. This study showed that the addition of carfilzomib to lenalidomide and dexamethasone resulted in significantly improved PFS at the interim analysis and had a favorable risk-benefit profile. ${ }^{46}$ Both studies have led to an extension in the FDA's license approval.

A number of other phase I and II studies have explored the role of carfilzomib in newly diagnosed patients. For example, the KRD combination has been explored in 53 newly diagnosed patients, where carfilzomib $(20,27$, or $36 \mathrm{mg} / \mathrm{m}^{2}$ on days $1,2,8,9,15$, and 16 and days $1,2,15$, and 16 after cycle 8 ), lenalidomide (25 mg days $1-21)$, and weekly dexamethasone (40/20 mg cycles $1-4 / 5+$ ) were given on a 28-day cycle. After cycle 4, transplant-eligible candidates underwent stem cell collection then continued KRD with the option of transplantation. The maximum planned dose level (carfilzomib $36 \mathrm{mg} / \mathrm{m}^{2}$ ) was expanded in phase II $(n=36)$. A total of 35 patients underwent stem cell collection, seven proceeded to transplantation, and the remainder resumed KRD. After a median of 12 cycles (range, 1-25), $62 \%$ achieved $\mathrm{nCR}$ and $42 \% \mathrm{SCR}$. With a median follow-up of 13 months, the 24-month PFS estimate was $92 \% .{ }^{47}$

Ixazomib, an orally bioavailable PI, was initially evaluated as a single agent in patients with relapsed disease who had limited prior exposure to bortezomib. ${ }^{48} \mathrm{~A}$ total of 33 patients were enrolled, and ixazomib was given at a dose of $5.5 \mathrm{mg}$ weekly for 3-4 weeks. Dexamethasone was added for lack of an MR by the end of cycle 2, lack of a PR by the end of cycle 4 , or for disease progression at any time. The most common AEs were thrombocytopenia, fatigue, nausea, and diarrhea. Dexamethasone was initiated in $22(67 \%)$ patients, 17 for not reaching the desired response, and five for progression. Response (PR) or greater to single-agent ixazomib was seen in five patients within four cycles of therapy including three patients with PR, one patient with CR, and one patient with SCR. Six additional patients with either an MR (two) or stable disease (four) achieved a PR after the addition of dexamethasone, translating to an OR rate of $34 \% .{ }^{48}$

A phase I/II trial to assess the safety, tolerability, and activity of ixazomib in combination with lenalidomide and dexamethasone in newly diagnosed patients with myeloma has also been reported ${ }^{49}$ Patients were treated with oral ixazomib (days 1, 8, and 15), lenalidomide $25 \mathrm{mg}$ (days 1-21), and dexamethasone $40 \mathrm{mg}$ (days $1,8,15$, and 22) for up to 12 28-day cycles, followed by maintenance therapy with ixazomib alone. A total of 65 patients were enrolled (15 to phase I and 50 to phase II). The maximum tolerated dose of ixazomib was established as $2.97 \mathrm{mg} / \mathrm{m}^{2}$, and the recommended phase II dose was $2.23 \mathrm{mg} / \mathrm{m}^{2}$, which was converted to a $4.0 \mathrm{mg}$ fixed dose based on the population pharmacokinetic results. Grade 3 or higher AEs included skin rashes (17\%), neutropenia (12\%), and thrombocytopenia $(8 \%)$. Drug-related peripheral neuropathy of grade 3 or higher occurred in $6 \%$ of patients. Importantly, $58 \%$ (95\% CI, 45-70) had a VGPR or better, demonstrating that the all oral combination of weekly ixazomib plus lenalidomide and dexamethasone was generally well tolerated and active in newly diagnosed patients.

A similar study of ixazomib in combination with lenalidomide and dexamethasone has also been reported in the relapsed setting. ${ }^{50}$ In this randomized study, patients received either ixazomib revlimid dexamethasone (IRD) or RD. Patients receiving IRD had a 35\% improvement in PFS compared to RD patients, and again patients with high-risk disease had a similar PFS when treated with IRD as low-risk patients, suggesting ixazomib may overcome the negative impact of cytogenetic abnormalities.

Based on these early results, it seems unlikely that bortezomib will be replaced by either carfilzomib or ixazomib, rather the PIs will remain a backbone of myeloma therapy and the most appropriate PI will be chosen for an individual patient. It is clear that although some of the side effects of the PIs are class effects (e.g., thrombocytopenia) others are related to the individual chemical structures/delivery mode of the different inhibitors (e.g., peripheral neuropathy, nausea, and diarrhea). Early data also suggest that the inhibitors may have difference effects in certain disease groups (e.g., carfilzomib may be more effective than bortezomib for high-risk disease; however, it is difficult to tell whether this is because the neuropathy symptoms were less and so patients could tolerate the long-term treatment better or whether it is truly more potent for this patient group). A third factor that will affect the use of the different proteasome inhibitors moving forward is cost, as more health care systems move toward value-based health care. Bortezomib will fall off its patent life in the coming years resulting in generic formulations becoming available, and this will no doubt play into health care decision making. From a clinical perspective, however, the results of ongoing clinical studies are eagerly awaited to help guide these treatment decisions and give further direction as to which PI is best for each disease phase based on both disease and patient factors.

\section{Conclusion}

The introduction of bortezomib for the treatment of myeloma has been one of the major breakthroughs in the 
care of patients with hematological malignancies in the past decade. Although the drug was first studied in the relapsed myeloma setting, its use quickly spread to the newly diagnosed transplant-eligible and transplant-ineligible setting, and it is now considered an important backbone therapy for all stages of the disease. In addition, data now support its use in Waldenstrom macroglobulinemia and other subtypes of lymphoma. Due to its novel mechanism of action and manageable side effect profile, it is effective in the treatment of high-risk myeloma disease subgroups (e.g., frail, elderly, renal failure, and poor-risk genetics). Much has been learnt about the most clinically effective way of delivering therapy, with patients often benefiting more from a triplet bortezomib combination compared to a doublet combination. As with any therapy, managing side effects quickly and efficiently when they occur is important, so that patients can continue on treatment and benefit from therapy. Therefore, proactive management of peripheral neuropathy and thrombocytopenia is advised using dose delay and reduction. The recent introduction of second- and third-generation PIs with different chemical and biological properties has resulted in a plethora of new clinical studies and has confirmed the ongoing role of this class of drug in future therapy.

\section{Acknowledgment}

This work was supported in part by a grant from the National Cancer Institute, National Institutes of Health (grant number, CA 55813).

\section{Disclosure}

FED has participated in advisory boards for Celgene, Takeda, Jansen, and Amgen. The other authors report no conflicts of interest in this work.

\section{References}

1. Barlogie B, Mitchell A, van Rhee F, Epstein J, Morgan GJ, Crowley J. Curing myeloma at last: defining criteria and providing the evidence. Blood. 2014;124(20):3043-3051.

2. Rajkumar SV, Richardson PG, Hideshima T, et al. Proteasome inhibition as a novel therapy target in human cancer. J Clin Oncol. 2005;23(3):639639. Review.

3. Aronson LI, Davies FE. DangER: protein ovERload. Targeting protein degradation to treat myeloma. Haematologica. 2012;97(8):1119-1130.

4. Qiang YW, Hu B, Chen Y, et al. Proteasome inhibitors and bone disease. Semin Hematol. 2012;49(3):243-248.

5. Richardson PG, Barlogie B, Berenson J, et al. A phase 2 study of bortezomib in relapsed, refractory myeloma. N Engl J Med. 2003; 348(26):2609-2617.

6. Richardson PG, Barlogie B, Berenson J, et al. Extended follow-up of a phase II trial in relapsed, refractory multiple myeloma: final time-toevent results from the SUMMIT trial. Cancer. 2006;106(6):1316-1319.

7. Richardson PG, Barlogie B, Berenson J, et al. Clinical factors predictive of outcome with bortezomib in patients with relapsed, refractory multiple myeloma. Blood. 2005;106(9):2977-2981.
8. Jagannath S, Barlogie B, Berenson JR, et al. Updated survival analyses after prolonged follow-up of the phase 2, multicenter CREST study of bortezomib in relapsed or refractory multiple myeloma. Br J Haematol. 2008;143(4):537-540.

9. Richardson PG, Sonneveld P, Schuster MW, et al. Bortezomib or highdose dexamethasone for relapsed multiple myeloma. $N$ Engl J Med. 2005;352(24):2487-2498.

10. Richardson PG, Sonneveld P, Schuster MW, et al. Reversibility of symptomatic peripheral neuropathy with bortezomib in the phase III APEX trial in relapsed multiple myeloma: impact of a dose-modification guideline. Br J Haematol. 2009;144(6):895-903.

11. Orlowski RZ, Nagler A, Sonneveld P, et al. Randomized phase III study of pegylated liposomal doxorubicin plus bortezomib compared with bortezomib alone in relapsed or refractory multiple myeloma: combination therapy improves time to progression. J Clin Oncol. 2007;25(25): 3892-3901.

12. Garderet L, Iacobelli S, Moreau P, et al. Superiority of the triple combination of bortezomib-thalidomide-dexamethasone over the dual combination of thalidomide-dexamethasone in patients with multiple myeloma progressing or relapsing after autologous transplantation: the MMVAR/IFM 2005-04 randomized phase III trial from the chronic leukemia working party of the European Group for Blood and Marrow Transplantation. J Clin Oncol. 2012;30(20): 2475-2482.

13. Richardson PG, Xie W, Jagannath S, et al. A phase 2 trial of lenalidomide, bortezomib, and dexamethasone in patients with relapsed and relapsed/refractory myeloma. Blood. 2014;123(10):1461-1469.

14. Moreau P, Pylypenko H, Grosicki S, et al. Subcutaneous versus intravenous bortezomib in patients with relapsed multiple myeloma: subanalysis of patients with renal impairment in the phase III MMY-3021 study. Haematologica. 2015;100(5):e207-e210.

15. Moreau P, Pylypenko H, Grosicki S, et al. Subcutaneous versus intravenous administration of bortezomib in patients with relapsed multiple myeloma: a randomised, phase 3, non-inferiority study. Lancet Oncol. 2011;12(5):431-440.

16. Richardson PG, Xie W, Mitsiades C, et al. Single-agent bortezomib in previously untreated multiple myeloma: efficacy, characterization of peripheral neuropathy, and molecular correlations with response and neuropathy. J Clin Oncol. 2009;27(21):3518-3525.

17. Barlogie B, Anaissie E, van Rhee F, et al. Incorporating bortezomib into upfront treatment for multiple myeloma: early results of total therapy 3. Br J Haematol. 2007;138(2):176-185.

18. Harousseau JL, Attal M, Avet-Loiseau H, et al. Bortezomib plus dexamethasone is superior to vincristine plus doxorubicin plus dexamethasone as induction treatment prior to autologous stem-cell transplantation in newly diagnosed multiple myeloma: results of the IFM 2005-01 phase III trial. J Clin Oncol. 2010;28(30):4621-4629.

19. Sonneveld P, Schmidt-Wolf IG, van der Holt B, et al. Bortezomib induction and maintenance treatment in patients with newly diagnosed multiple myeloma: results of the randomized phase III HOVON-65/ GMMG-HD4 trial. J Clin Oncol. 2012;30(24):2946-2955.

20. Cavo M, Tacchetti P, Patriarca F, et al. Bortezomib with thalidomide plus dexamethasone compared with thalidomide plus dexamethasone as induction therapy before, and consolidation therapy after, double autologous stem-cell transplantation in newly diagnosed multiple myeloma: a randomised phase 3 study. Lancet. 2010;376(9758): 2075-2085.

21. Sonneveld P, Goldschmidt H, Rosiñol L, et al. Bortezomib-based versus nonbortezomib-based induction treatment before autologous stem-cell transplantation in patients with previously untreated multiple myeloma: a meta-analysis of phase III randomized, controlled trials. J Clin Oncol. 2013;31(26):3279-3287.

22. Moreau P, Hulin C, Macro M, et al. VTD is superior to VCD prior to intensive therapy in multiple myeloma: results of the prospective IFM2013-04 trial. Blood. 2016;127(21):2569-2574.

23. Richardson PG, Weller E, Lonial E, et al. Lenalidomide, bortezomib, and dexamethasone combination therapy in patients with newly diagnosed multiple myeloma. Blood. 2010;116(5):679-686. 
24. San Miguel JF, Schlag R, Khuageva NK, et al. Bortezomib plus melphalan and prednisone for initial treatment of multiple myeloma. $N E n g l$ J Med. 2008;359(9):906-917.

25. Mateos MV, Oriol A, Martinez-López J, et al. Bortezomib, melphalan, and prednisone versus bortezomib, thalidomide, and prednisone as induction therapy followed by maintenance treatment with bortezomib and thalidomide versus bortezomib and prednisone in elderly patients with untreated multiple myeloma: a randomised trial. Lancet Oncol. 2010;11(10):934-941.

26. Durie B, Hoering A, Rajkumar V, et al. Bortezomib, lenalidomide and dexamethasone vs. lenalidomide and dexamethasone in patients with previously untreated multiple myeloma without an intent for immediate autologous stem cell transplant (ASCT): results of the randomized phase III trial SWOG S0777. Blood. 2015;126(23):25.

27. Augustson BM, Begum G, Dunn JA, et al. Early mortality after diagnosis of multiple myeloma: analysis of patients entered onto the United Kingdom Medical Research Council trials between 1980 and 2002 - Medical Research Council Adult Leukaemia Working Party. J Clin Oncol. 2005;23(36):9219-9226.

28. Bladé J, Fernández-Llama P, Bosch F, et al. Renal failure in multiple myeloma: presenting features and predictors of outcome in 94 patients from a single institution. Arch Intern Med. 1998;158(17): 1889-1893.

29. Chanan-Khan AA, Kaufman JL, Mehta J, et al. Activity and safety of bortezomib in multiple myeloma patients with advanced renal failure: a multicenter retrospective study. Blood. 2007;109(6):2604-2606.

30. Larocca A, Palumbo A. How I treat fragile myeloma patients. Blood. 2015;31:2015-2015

31. Niesvizky R, Flinn IW, Rifkin R, et al. Community-based phase IIIB trial of three UPFRONT bortezomib-based myeloma regimens. J Clin Oncol. 2015;33(33):3921-3929.

32. Bergsagel PL, Mateos MV, Gutierrez NC, Rajkumar SV, San Miguel JF. Improving overall survival and overcoming adverse prognosis in the treatment of cytogenetically high-risk multiple myeloma. Blood. 2013; 121(6):884-892.

33. Avet-Loiseau H. Ultra high-risk myeloma. Hematology Am Soc Hematol Educ Program. 2010;2010:489-493.

34. Jagannath S, Richardson PG, Sonneveld P, et al. Bortezomib appears to overcome the poor prognosis conferred by chromosome 13 deletion in phase 2 and 3 trials. Leukemia. 2007;21(1):151-157.

35. Nair B, van Rhee F, Shaughnessy JD Jr, et al. Superior results of total therapy 3 (2003-33) in gene expression profiling-defined low-risk multiple myeloma confirmed in subsequent trial 2006-66 with VRD maintenance. Blood. 2010;115(21):4168-4173.

36. Weinhold N, Heuck CJ, Rosenthal A. Clinical value of molecular subtyping multiple myeloma using gene expression profiling. Leukemia. 2016;30(4):883-888.

37. Dimopoulos M, Siegel DS, Lonial S, et al. Vorinostat or placebo in combination with bortezomib in patients with multiple myeloma (VANTAGE 088): a multicentre, randomised, double-blind study. Lancet Oncol. 2013;14(11):1129-1140.
38. San-Miguel JF, Hungria VT, Yoon SS, et al. Panobinostat plus bortezomib and dexamethasone versus placebo plus bortezomib and dexamethasone in patients with relapsed or relapsed and refractory multiple myeloma: a multicentre, randomised, double-blind phase 3 trial. Lancet Oncol. 2014;15(11):1195-1206.

39. Richardson PG, Schlossman RL, Alsina M, et al. PANORAMA 2: panobinostat in combination with bortezomib and dexamethasone in patients with relapsed and bortezomib-refractory myeloma. Blood. 2013; 122(14):2331-2337.

40. Richardson PG, Briemberg H, Jagannath S, et al. Frequency, characteristics, and reversibility of peripheral neuropathy during treatment of advanced multiple myeloma with bortezomib. J Clin Oncol. 2006; 24(19):3113-3120.

41. Lonial S, Waller EK, Richardson PG, et al. Risk factors and kinetics of thrombocytopenia associated with bortezomib for relapsed, refractory multiple myeloma. Blood. 2005;106(12):3777-3784.

42. Nucci M, Anaissie E. Infections in patients with multiple myeloma in the era of high-dose therapy and novel agents. Clin Infect Dis. 2009; 49(8):1211-1225.

43. Chanan-Khan A, Sonneveld P, Schuster MW, et al. Analysis of herpes zoster events among bortezomib-treated patients in the phase III APEX study. J Clin Oncol. 2008;26(29):4784-4790.

44. Jagannath S, Vij R, Stewart AK, et al. An open-label single-arm pilot phase II study (PX-171-003-A0) of low-dose, single-agent carfilzomib in patients with relapsed and refractory multiple myeloma. Clin Lymphoma Myeloma Leuk. 2012;12(5):310-318.

45. Dimoupoulos MA, Moreau P, Palumbo A, et al. Carfilzomib and dexamethasone versus bortezomib and dexamethasone for patients with relapsed or refractory multiple myeloma (ENDEAVOR): a randomised, phase 3, open-label, multicentre study. Lancet Oncol. 2016;17(1):27-38.

46. Stewart AK, Rajkumar SV, Dimopoulos MA, et al. Carfilzomib, lenalidomide, and dexamethasone for relapsed multiple myeloma. $N$ Engl J Med. 2015;372(2):142-152.

47. Jakubowiak AJ, Dytfeld D, Griffith KA, et al. A phase 1/2 study of carfilzomib in combination with lenalidomide and low-dose dexamethasone as a frontline treatment for multiple myeloma. Blood. 2012; 120(9):1801-1809.

48. Kumar SK, LaPLant B, Roy V, et al. Phase 2 trial of ixazomib in patients with relapsed multiple myeloma not refractory to bortezomib. Blood Cancer J. 2015;4:e338.

49. Kumar SK, Berdeja JG, Niesvizky R, et al. Safety and tolerability of ixazomib, an oral proteasome inhibitor, in combination with lenalidomide and dexamethasone in patients with previously untreated multiple myeloma: an open-label phase 1/2 study. Lancet Oncol. 2014;15(13):1503-1512.

50. Moreau P, Masszi T, Grzasko N, et al. Oral ixazomib, lenalidomide and dexamethasone for multiple myeloma. $N$ Engl J Med. 2016;374(17): 1621-1634.

51. National Cancer Institute. Common Terminology Criteria for Adverse Events v3.0 (CTCAE). Available from: https://ctep.cancer.gov/protocoldevelopment/electronic_applications/docs/ctcaev3.pdf. Accessed January $27,2017$.
Cancer Management and Research

\section{Publish your work in this journal}

Cancer Management and Research is an international, peer-reviewed open access journal focusing on cancer research and the optimal use of preventative and integrated treatment interventions to achieve improved outcomes, enhanced survival and quality of life for the cancer patient. The manuscript management system is completely online and includes

\section{Dovepress}

a very quick and fair peer-review system, which is all easy to use. Visit http://www.dovepress.com/testimonials.php to read real quotes from published authors. 